\title{
The Chemical Information Contained in the EXAFS Debye-Waller Factor: Covalency in Iron(III) Bis-diketonato Complexes
}

\author{
Matthias Bauer* \\ Institute of Technical Chemistry and Polymerchemistry, Karlsruhe Institute of Technology - Campus South, \\ Engesserstrasse 18, 76128 Karlsruhe, Germany
}

Received: August 23, 2010; Revised Manuscript Received: October 12, 2010

\begin{abstract}
A new procedure to extract chemical information from EXAFS spectroscopy beyond the classic parameters, such as coordinating atoms, coordination numbers, and bond distances, by thorough analysis of the Debye-Waller-like factor is presented. In a comparative study of different iron(III) bis-diketonato complexes, which are highly relevant for the iron-catalyzed Michael addition reaction, the degree of covalency of the $\mathrm{Fe}-\mathrm{O}$ bond between the iron center and the ligand is determined by a combined EXFAS, Raman, and UV/ vis spectroscopic approach. A detailed description of the methodology is presented, and it will demonstrated that the comparative degree of covalency is correlated to the $\mathrm{p} K_{\mathrm{a}}$ value of the coordinating diketone. Moreover, it is shown that the distinct catalytic activity of the diketones can not be explained by differences of the covalency of the iron-ligand $\mathrm{Fe}-\mathrm{O}$ bond.
\end{abstract}

\section{Introduction}

The manifold role of 1,3 -diketones and $\beta$-keto esters in chemistry is undoubted, as they can be found in many fields like materials ${ }^{1}$ and sol-gel chemistry ${ }^{2}$ or catalysis. ${ }^{3}$ A prominent example in catalysis, where metal bis-diketonato complexes have been identified as catalytically active compound is the ironcatalyzed Michael addition reaction. ${ }^{4}$ Broad screening of $\beta$-keto esters and 1,3-diketones (generally referred to as diktones in the following) proved the practicability of $\mathrm{C}-\mathrm{C}$ coupling for a wide range of reactants, ${ }^{5}$ with the best results for cyclic $\beta$-keto esters (cf. scheme 1). From mass spectrometric measurements, the cyclic $\beta$-keto ester was found to exhibit the highest iron affinity in comparison to all other investigated compounds. ${ }^{6}$ With the present paper, further investigations into the binding properties of iron bis-diketonato complexes will be given by means of EXAFS spectroscopy, in which a completely new procedure of data analysis is applied, making use of a combined Raman/EXAFS approach in order to analyze the so-called EXAFS Debye-Waller-like factor (DWF) in such a way that new insights into the catalytic activity of different diketonates in the iron-catalyzed Michael addition reaction can be provided. This will be achieved by comparative determination of the degree of covalency in different iron bis-diketonato complexes.

Despite the fact that Extended X-ray Absorption Fine Structure (EXAFS) spectroscopy is mainly used to extract the geometric structure around a central metal atom, it will be shown here that more subtle chemical information is contained in the so-called Debye-Waller-like factor (DWF), which accounts for disorder effects in EXAFS spectra. ${ }^{7}$ In general, the DWF is constituted by two parts, a static and a vibrational disorder term as given in eq $1 .^{7}$

$$
\sigma=\sigma_{\text {stat }}+\sigma_{\text {vib }}
$$

Since the static part $\sigma_{\text {stat }}$ presents the deviation from the mean structural motif, it is more relevant for studies of solid state

* To whom correspondence should be addressed. Phone: +49721608 4320. E-mail: matthias.bauer@kit.edu. materials that contain amorphous structures. Here the relevance of the vibrational DWF $\sigma_{\text {vib }}$ for studies of molecular transition metal complexes is focused.

Equation 2 interrelates the vibrational DWF $\sigma_{\text {vib, }}$, which is the mean-square relative displacement MSRD with the meansquare displacements MSD $\left\langle\left(\vec{r}_{i}\right)^{2}\right\rangle+\left\langle\left(\vec{r}_{0}\right)^{2}\right\rangle$ and the displacement correlation function DCF $\left(\left\langle\vec{r} \vec{u}_{i}\right\rangle\left\langle\vec{r}_{0}\right\rangle\right){ }^{8}$

$$
\sigma_{\text {vib }}=\left\langle\left(\vec{r} \vec{u}_{j}\right)^{2}\right\rangle+\left\langle\left(\vec{r} \vec{u}_{0}\right)^{2}\right\rangle-2\left(\left\langle\vec{r} \vec{u}_{j}\right\rangle\left\langle\vec{r} \vec{u}_{0}\right\rangle\right)
$$

In contrast to the Debye-Waller factor obtained by X-ray Diffraction, which measures the mean-square displacement of each atom from its individual atomic positions, the DWF obtained by EXAFS spectroscopy provides the mean-square relative displacement between the X-ray absorbing and back-

\section{SCHEME 1: Diketones and Keto-Esters Used in the} Study ${ }^{a}$
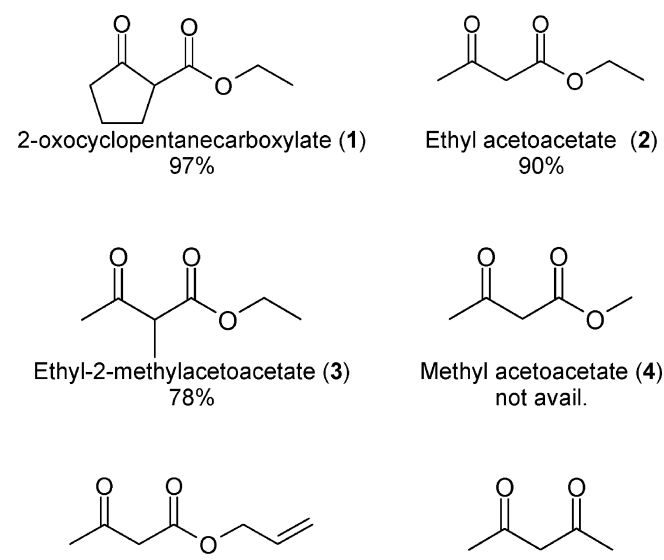

Allyl acetoacetate (5) not avail.

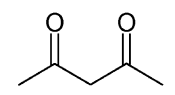

Acetylacetone (6) $77 \%$.

${ }^{a}$ Where available, the experimental yields of product obtained in the iron-catalyzed Michael addition reaction are given. ${ }^{5}$ 
scattering atom along the bond direction. ${ }^{7}$ Since the relative displacement between the absorber and the backscatterer is measured with the EXAFS-DWF, it is sensitive to correlated movements of this atom pair, that is, anisotropic vibration. In eq 2, the anisotropy is accounted for by the displacement correlation factor DCF. In case of purely isotropic vibrations, a DCF of zero would be found. As anisotropy in molecular complexes is introduced by covalency of the bond between the metal center and the ligand, the DCF presents a direct probe to compare the degree of covalency in complexes of the same type but with ligands of different chemical character. With the present work it is attempted to extract a qualitative comparison of covalency in iron bis-diketonato complexes reflected in the value of the DCF, and to correlate it to the chemical nature of the coordinating diketonate ligand as measured by the acidic strength or the $\mathrm{p} K_{\mathrm{a}}$ value.

The methodic approach to achieve this aim is outlined in the following.

In the harmonic oscillator approximation, the isotropic mean square amplitude of an isolated vibration between two atoms is calculated according to ${ }^{9}$

$$
\left\langle Q^{2}\right\rangle=\frac{h^{2}}{8 \pi v \mu^{2}} \cot h\left(\frac{h v}{2 k T}\right)
$$

where $\mu$ is the reduced mass of the oscillator pair, and $v$ is the vibrational frequency. In absence of static disorder, it is equal to the MSD: ${ }^{10}$

$$
\left\langle Q^{2}\right\rangle=\left\langle\left(\vec{r} \vec{u}_{j}\right)^{2}\right\rangle+\left\langle\left(\vec{r} \vec{u}_{0}\right)^{2}\right\rangle
$$

Since the vibrational frequency can be determined from Raman-spectroscopic measurements, the value of the MSD is easily obtained. On the other hand, the (MSRD) $\sigma_{\text {vib }}$ of a known structure is measured by the EXAFS-DWF, and (2) can be reformulated as:

$$
2\left(\left\langle\vec{r} \vec{u}_{j}\right\rangle\left\langle\vec{r} \vec{u}_{0}\right\rangle\right)=\frac{h^{2}}{8 \pi v \mu^{2}} \cot h\left(\frac{h v}{2 k T}\right) \sigma_{\text {vib }}
$$

With this relation, the DCF, and therefore a measure of the degree of covalency is available by combined XAFS and Raman measurements.

Use of the presented correlations is made in by investigation of equimolar solutions of the iron salt $\mathrm{Fe}\left(\mathrm{ClO}_{4}\right)_{3} \cdot 9 \mathrm{H}_{2} \mathrm{O}$ in different $\beta$-keto esters and 1,3-diketones, which are shown in Scheme 1. These solvents, which act also as ligands, are all relevant for the iron-catalyzed Michael addition reaction. However, their reactivities are different (cf. Scheme 1). Therefore, a systematic study of the DWF focused on the displacement correlation factor for the example of iron bis-diketoneato complexes will be presented. Both new fundamental insights into this parameters, a correlation with chemical properties of the diketone and possible new explanations for the different reactivities in the Michael addition reaction will be provided.

\section{Experimental Section}

2.1. Materials. All compounds were purchased from SigmaAldrich and purified by distillation, except the iron salt $\mathrm{Fe}\left(\mathrm{ClO}_{4}\right)_{3} \cdot 9 \mathrm{H}_{2} \mathrm{O}$, which was used as received. All diketones were used as solvent. $300 \mathrm{mg}$ of $\mathrm{Fe}\left(\mathrm{ClO}_{4}\right)_{3} \cdot 9 \mathrm{H}_{2} \mathrm{O}$ were dissolved in $2 \mathrm{~mL}$ of diketone to achieve a concentration of approximately $0.3 \mathrm{~mol} / \mathrm{L}$. Experimental parameters of the measurements were identical for all samples.

2.2. EXAFS Measurements and Data Analysis. EXAFS measurements were performed at beamline E4 at HASYLAB (Hamburg) under ambient conditions at $20^{\circ} \mathrm{C}$. A Si(111) double crystal monochromator was used for measurements at the Fe K-edge $(7.112 \mathrm{keV})$. The second monochromator crystal was tilt for optimal harmonic rejection. The energy resolution for the Fe K-edge energy is estimated to $1.0 \mathrm{eV}$. The spectra were recorded in transmission mode with ionization chambers. All three chambers were filled with nitrogen gas. The individual pressures were adjusted to optimize the signal-to-noise ratio. Energy calibration was performed with an iron metal foil. To avoid errors in the XANES region due to small changes in the energy calibration between two measurements, all spectra were corrected to the theoretical edge energy of iron foil, which was measured every scan. Liquid samples were measured in a specially designed transmission sample cell. ${ }^{11}$ Five spectra of each sample were averaged in order to reduce the spectral noise as well as to check for changes in course of the measurements.

Data evaluation started with background absorption removal from the experimental absorption spectrum by subtracting a Victoreen-type polynomial with the WINXAS program package. ${ }^{12 a}$ The background-subtracted spectrum was then convoluted with a series of increasingly broader Gauss functions and the common intersection point was taken as energy $E_{0} .{ }^{12 \mathrm{~b}}$ To determine the smooth part of the spectrum, corrected for pre-edge absorption, a piecewise polynomial was used. It was adjusted in such a way that the low- $R$ components of the resulting Fourier transform were minimal. After division of the background-subtracted spectrum by its smooth part, the photon energy was converted to photoelectron wave numbers $k$. The resulting $\chi(k)$-function was weighted with $k^{3}$. Data analysis was performed in $k$-space according to the curved wave formalism. ${ }^{13}$ EXCURV98 with XALPHA phase and amplitude functions was used to fit the data. ${ }^{13 a}$ Like other programm codes (e.g., GNXAS $^{13 b}$ ) the EXAFS spectra are analyzed in terms of radial distribution functions (RDF), which is different from the pathby-path approach as for example provided in feff. ${ }^{13 \mathrm{c}}$ As such, all atoms included in one shell of the RDF possess the same Debye-Waller like factor. Multiple scattering effects were not taken into account, ${ }^{13 \mathrm{~d}}$ since the analyzed nearest neighbor shell is not affected by multiple scattering contributions. Double channel excitations were not accounted for. ${ }^{13 e}$ Although this could introduce a source of error, all samples should be affected in the same manner, due to the identical nature of the investigated complexes, which does not affect the results of a comparative study as presented here.

The mean free path of the scattered electrons was calculated from the imaginary part of the potential (VPI set to -4.00 ). The amplitude reduction factor was adjusted to $\mathrm{AF}=0.8$ using the known XRD data of $\mathrm{Fe}(\mathrm{acac})_{3} \cdot{ }^{14} \mathrm{~A}$ correction factor $E_{\mathrm{f}}$ to account for shifts in energy between the theoretical and experimental spectra was used. Since the nearest neighbor $\mathrm{Fe}-\mathrm{O}$ shells are the subject of the present study, no multiple scattering (MS) was considered in the data analysis, as these shells can not be affected by such MS.

Fourier filtering in the range of $1-3.5 \AA$ was applied to remove random noise, and analysis was carried out on the backtransformed $k^{3} \chi(k)$ functions. Although a strong correlation between the EXAFS DWF and coordination numbers is wellknown, which in the present study would lead to a strong uncertainty of the obtained results, the results of the conducted 
SCHEME 2: Sketch of the Structural Model Used to Fit the Experimental EXAFS Spectra of the Studied Bis-diketonate Complexes ${ }^{a}$

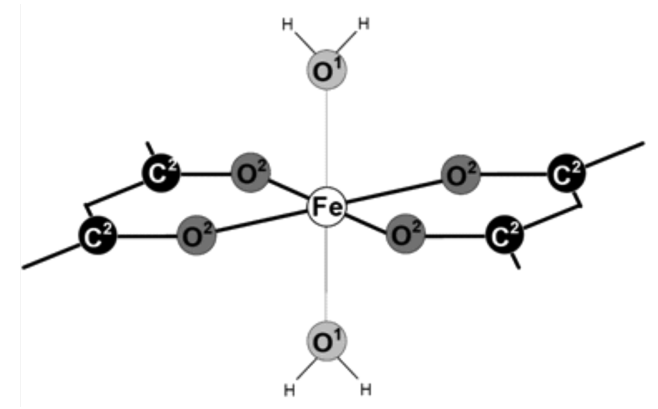

${ }^{a}$ Exponent "1" refers to water, and "2" to the diketonate ligand.

Raman and UV/vis measurements allow to break this correlation, since they unambiguously prove the coordination of two diketonate ligands to the iron center in each investigated sample (cf. Section 3).

Due to the evident formation of bis-diketoneato complexes $\left[\mathrm{Fe}^{\mathrm{III}}(\mathrm{DK})_{2}\left(\mathrm{H}_{2} \mathrm{O}\right)_{2}\right]^{-}(\mathrm{DK}=$ diketoneate anion $),{ }^{4}$ a threedimensional model according to scheme 2 with the diketonate groups in the equatorial and the water ligands in epical position was consequently applied to fit the EXAFS data. The coordination numbers of the $\mathrm{Fe}-\mathrm{O}^{1} \mathrm{H}_{2}, \mathrm{Fe}-\mathrm{O}^{2}-\mathrm{DK}$ and $\mathrm{Fe}-\mathrm{C}^{2}-\mathrm{DK}$ shells were set according to the UV/vis and Raman results to two, four, and four, respectively. In the fitting procedure, the distances, DWF and $E_{\mathrm{f}}$ were iterated. Several starting sets of values were applied to check the reliability of obtained values. The results were reproducable in every case. It was thus possible to separate the $\mathrm{Fe}-\mathrm{O}^{2}-\mathrm{DK}$ DWF from the $\mathrm{Fe}-\mathrm{O}^{1} \mathrm{H}_{2} \mathrm{DWF}$, which is a prerequisite for the following extraction of $\mathrm{Fe}-$ diketonate bond characteristics.

2.3. Raman Measurements. Raman spectra were recorded with a Bruker RFS 100/S Fourier Transform spectrometer with an air-cooled NIR Nd:YAG laser with a wavelength of 1064 $\mathrm{nm}$ and a power between $50-800 \mathrm{~mW}$. The scattered light intensity was recorded with a high-sensitivity Ge diode (cooled with liquid nitrogen). For each spectrum 1000 scans were accumulated (spectral resolution $4 \mathrm{~cm}^{-1}$ ). A Raman quartz cuvette was used.

For the analysis, difference Raman spectra were used. They were obtained by subtracting the bands of the pure solvent from the spectrum of $\mathrm{Fe}\left(\mathrm{ClO}_{4}\right)_{3} \cdot 9 \mathrm{H}_{2} \mathrm{O}$ in the respective solvent. Scaling was carried out by means of a vibration band of the solvent, which is not interfered by a signal related to $\mathrm{Fe}\left(\mathrm{ClO}_{4}\right)_{3} \cdot 9 \mathrm{H}_{2} \mathrm{O}$ or the formed diketoneato complex. Since the scaling of Raman intensities is not linear over the complete spectral range, this can lead to negative intensities in the difference spectra at some point. However, this factdoes not influence the position of the Raman signals that were used. The Raman spectra of all investigated samples are shown in the ESI (figure SI1).

2.4. UV/vis Measurements. UV-vis-measurements were recorded with an Ocean Optics USB2000 CCD spectrometer on a spectral range of $200-850 \mathrm{~nm}$ at ambient conditions (20 $\left.{ }^{\circ} \mathrm{C}\right)$ with a spectral resolution of $2.5 \mathrm{~nm}(600 \mathrm{~L} / \mathrm{mm}$ grating, 2048 pixel CCD, $50 \mu \mathrm{m}$ slit), using a optically transparent cuvette in a cuvette holder as provided by OceanOptics. The UV/vis spectra of all shown samples are shown in the ESI (Supporting Information, Figure SI1).

\section{Results}

In advance of the Debye-Waller factor analysis, prove has to be given, that the same kind of complexes are formed by each
TABLE 1: Spectroscopic Data of the Investigated Solutions with Diketones Given in Scheme 1

\begin{tabular}{ccccc}
\hline solution & $\begin{array}{c}\text { bis-diketonato } \\
\text { UV/vis } \\
\text { band }(\mathrm{nm})\end{array}$ & $\begin{array}{c}\text { bis-diketonato } \\
\text { Raman bands } \\
\left(\mathrm{cm}^{-1}\right)\end{array}$ & $\begin{array}{c}\text { isolated Fe-O } \\
\text { Raman band } \\
\left(\mathrm{cm}^{-1}\right)\end{array}$ & $\left(Q^{2}\right) / 10^{-23} \mathrm{~m}^{2}$ \\
\hline $\mathbf{1}$ & 514 & $464^{a}, 1572^{b}$ & 272.02 & 8.539 \\
$\mathbf{2}$ & 448 & 462,1576 & 262.38 & 9.099 \\
$\mathbf{3}$ & 480 & 462,1574 & 275.88 & 8.331 \\
$\mathbf{3}$ & 484 & 464,1578 & 260.45 & 9.219 \\
$\mathbf{5}$ & 452 & 466,1577 & 250.81 & 9.859 \\
$\mathbf{6}$ & 444 & 456,1600 & 272.02 & 8.539 \\
${ }^{a}$ Coupled Fe-O/C-C vibration. ${ }^{4,15,16}{ }^{b} \mathrm{C}-\mathrm{O}$ vibration. &
\end{tabular}

diketone and $\mathrm{Fe}\left(\mathrm{ClO}_{4}\right)_{3} \cdot 9 \mathrm{H}_{2} \mathrm{O}$. It is well-known, that upon dissolving iron salts in 1,3-diketones (including $\beta$-keto esters), only the bis-diketoneates are formed. Tris-diketonates are only accessibly if a base is added..$^{15}$ Mono-, bis-, and tris-diketonates can be well distinguished spectroscopically by their characteristic $\mathrm{Fe}-\mathrm{O} / \mathrm{C}-\mathrm{C}$ and $\mathrm{C}-\mathrm{O}$ vibration ${ }^{4,15,16}$ and their $\mathrm{UV} /$ vis absorption band., ${ }^{4,15,16}$

The spectroscopic data for all investigated coomplexes are listed in Table 1 and they leave no doubt that bis-diketoneate complexes of iron are present. ${ }^{4,15}$ Therefore, the EXAFS spectra could be fitted in a sound manner by setting the coordination numbers according to scheme 2 , that is, two water oxygen, four diketonate oxygen, and four diketonate carbon atoms, while iterating the distances for the $\mathrm{Fe}-\mathrm{O}^{1} \mathrm{H}_{2}, \mathrm{Fe}-\mathrm{O}^{2}-\mathrm{DK}(\mathrm{DK}=$ diketone residue), and $\mathrm{Fe}-\mathrm{C}^{2}-\mathrm{DK}$ backscattering atoms.

By application of this procedure, the contribution of the water ligands to the $\mathrm{Fe}-\mathrm{O}$ DWF can be separated out, which is mandatory for an isolated analysis of the iron-diketonate $\mathrm{Fe}-\mathrm{O}-\mathrm{DK}$ bond characteristics. The results of this EXAFS analysis are given in Table 2, the Fourier transformed spectra of the $\mathrm{Fe}-\mathrm{O}$ shell are shown in Figure 1, the raw spectra and the quality of the fits are shown in the Supporting Information, Figures SI2 and SI3, respectively.

The bond distances are in good agreement with documented values ${ }^{4}$ for $\mathrm{Fe}-\mathrm{O}^{1} \mathrm{H}_{2}$ and $\mathrm{Fe}-\mathrm{O}^{2}-\mathrm{DK}$ bonds, comparing the values obtained for the different diketones, they are identical within the error bar, supporting the conclusion of identical coomplexes as drawn form UV/vis and Raman spectrscopy. In contrast, the DWF for the $\mathrm{Fe}-\mathrm{O}^{2}-\mathrm{DK}$ bonds differ significantly in the range of $7.6-13.1 \times 10^{-3} \AA^{2}$, which is the basis for the following analysis, whereas the DWF of the $\mathrm{Fe}-\mathrm{O}^{1} \mathrm{H}_{2}$ group are only silightly varing in the range of $(4.9-6.9) \times 10^{-3} \AA^{2}$. The obtained DWFs are equal to the MSRD in eq 2.

The value of the MSD is then calculated according to eq 3 from the isolated $\mathrm{Fe}-\mathrm{O}^{2}-\mathrm{DK}$ vibration of the individual complexes, which can be found in the range of $260-280 \mathrm{~cm}^{-1} .16$ All parameters needed for and resulting from this step are listed in Table 1.

From the values of the MSRD (EXAFS Debye-Waller factor), the MSD (by Raman spectroscopy), the DCF (difference between MSRD and MSD) as a measure of covalency of the $\mathrm{Fe}-\mathrm{O}^{2}-\mathrm{DK}$ bond can then be calculated, as summarized in Table 3. Additionally, the $\mathrm{p} K_{\mathrm{a}}$ values of the diketones used are also given in Table 3. They were calculated using the Advanced Chemistry Development (ACD/Laboratories) Software V8.14 for Solaris.

A plot of the DCF $=2\left\langle\left(\vec{r}_{0}\right)\left(\vec{r} \vec{r}_{j}\right)\right\rangle$ against the $\mathrm{p} K_{\mathrm{a}}$ values of the diketones is given in Figure 2. The corresponding regression function was determined to be DCF $=-0.0017( \pm 0.0006) \mathrm{p} K_{\mathrm{a}}$ $+0.0257( \pm 0.0062)$ with a correlation factor of $R=0.835$, that is, a significant correlation bewtween the DCF and the $K_{\mathrm{a}}$ is found. In a careful error analysis all complexes except with allyl acetoacetate (5) are found to lie on the linear regression curve within the error bars. It is also only the complex with diketone 
TABLE 2: Structural Parameters from Fitting the EXAFS Spectra of $\mathrm{Fe}\left(\mathrm{ClO}_{4}\right)_{3}$ Solutions in Different 1,3-Diketones, Given in Scheme $1^{a}$

\begin{tabular}{|c|c|c|c|c|c|c|}
\hline solution & abs-bs ${ }^{b}$ & $N(\mathrm{Bs})^{c}$ & $R(\AA)^{d}$ & $\sigma 2(2 \AA 2)^{e}$ & fit index ${ }^{f}$ & $\begin{array}{c}\text { k-range }(\AA),{ }^{-1} \\
\operatorname{Ef}(\mathrm{eV})\end{array}$ \\
\hline \multirow{2}{*}{1} & $\mathrm{Fe}-\mathrm{O} 1$ & 4 & $1.965 \pm 0.020$ & $0.01298 \pm 0.0019$ & 16.92 & $3.3-15.1$ \\
\hline & $\mathrm{Fe}-\mathrm{O} 2$ & 2 & $2.080 \pm 0.021$ & $0.00693 \pm 0.0010$ & & 7.47 \\
\hline \multirow[t]{3}{*}{2} & $\mathrm{Fe}-\mathrm{O} 1$ & 4 & $1.951 \pm 0.020$ & $0.01061 \pm 0.0016$ & 19.62 & $3.3-15.1$ \\
\hline & $\mathrm{Fe}-\mathrm{O} 2$ & 2 & $2.065 \pm 0.021$ & $0.00541 \pm 0.0008$ & & 8.28 \\
\hline & $\mathrm{Fe}-\mathrm{C} 2$ & 4 & $2.872 \pm 0.029$ & $0.02490 \pm 0.0050$ & & \\
\hline \multirow[t]{3}{*}{4} & $\mathrm{Fe}-\mathrm{O} 1$ & 4 & $1.957 \pm 0.020$ & $0.01308 \pm 0.0019$ & 28.73 & $3.3-15.1$ \\
\hline & $\mathrm{Fe}-\mathrm{O} 2$ & 2 & $2.044 \pm 0.020$ & $0.00839 \pm 0.0013$ & & 8.95 \\
\hline & $\mathrm{Fe}-\mathrm{C} 2$ & 4 & $2.847 \pm 0.029$ & $0.02490 \pm 0.0046$ & & \\
\hline \multirow[t]{3}{*}{5} & $\mathrm{Fe}-\mathrm{O} 1$ & 4 & $1.955 \pm 0.020$ & $0.01025 \pm 0.0015$ & 18.31 & $3.3-15.1$ \\
\hline & $\mathrm{Fe}-\mathrm{O} 2$ & 2 & $2.065 \pm 0.021$ & $0.00514 \pm 0.0008$ & & 8.29 \\
\hline & $\mathrm{Fe}-\mathrm{C} 2$ & 4 & $2.863 \pm 0.029$ & $0.02493 \pm 0.0047$ & & \\
\hline
\end{tabular}

${ }^{a}$ Amplitude reducing factor $(\mathrm{AFAC})=0.8 .{ }^{b}$ abs $=\mathrm{X}$-ray absorbing atom, bs $=$ backscattering atom. ${ }^{c}$ Number of backscattering atoms, fixed according to the results of UV/vis and Raman spectroscopic results. ${ }^{d}$ Bond length abs-bs. ${ }^{e}$ DWF (MSRD). ${ }^{f}$ Quality of fit.

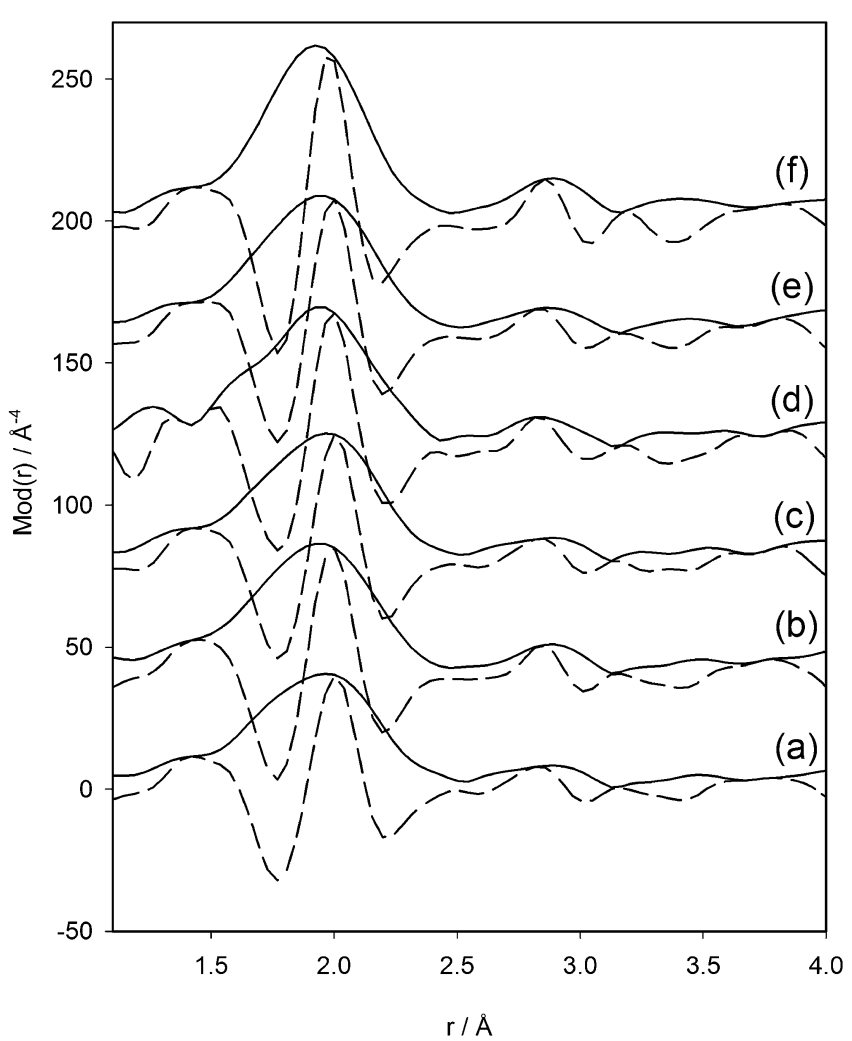

Figure 1. Fourier transformed oxygen signal of the solutions of $\mathrm{Fe}\left(\mathrm{ClO}_{4}\right)_{3} \cdot 9 \mathrm{H}_{2} \mathrm{O}$ in 1 (a), 2 (b), 3 (c), 4 (d), 5 (e), and 6 (f). The corresponding phases are shown as dotted lines.

5 that can not be found within a $95 \%$ confidence interval. A reason for this might be the allyl group that is able to interact with the iron center by its $\pi$-molecular orbitals.

\section{Discussion}

From Figure 2 it can be seen, that the obtained DCF values can be divided into three groups which follow the chemical classification of the used ligands: Acetylacetone (6) is an unsubstituted, symmetric 1,3-diketone with a $\mathrm{p} K_{\mathrm{a}}$-value of about 9 and shows a high DCF value; ethyl acetoacetate (2), methyl acetoacetate (4), and allyl acetoacetate (5) are unsubstituted
TABLE 3: MSRD (From EXAFS Measurements), MSD (From Raman Measurements) and the Resulting DCF of the $\mathrm{Fe}-\mathrm{O2}-\mathrm{DK}$ Bond, Together with the Corresponding $\mathrm{pK}_{\mathrm{a}}$ Values

\begin{tabular}{ccccr}
\hline $\begin{array}{c}\text { solution of } \\
\mathrm{Fe}\left(\mathrm{ClO}_{4}\right)_{3} \\
\text { with ligand }\end{array}$ & MSRD $\left(\AA^{2}\right)$ & MSD $\left(\AA^{2}\right)$ & DCF $\left(\AA^{2}\right)$ & $\mathrm{p} K_{\mathrm{a}}$ \\
\hline 1 & 0.01298 & 0.0171 & $0.0041 \pm 0.0019$ & $12.06 \pm 0.5$ \\
2 & 0.01061 & 0.0182 & $0.0076 \pm 0.0015$ & $10.69 \pm 0.5$ \\
3 & 0.01185 & 0.0167 & $0.0048 \pm 0.0017$ & $11.98 \pm 0.5$ \\
4 & 0.01308 & 0.0184 & $0.0054 \pm 0.0019$ & $10.67 \pm 0.5$ \\
5 & 0.01025 & 0.0197 & $0.0095 \pm 0.0015$ & $10.52 \pm 0.5$ \\
6 & 0.00755 & 0.0171 & $0.0095 \pm 0.0011$ & $8.94 \pm 0.1$
\end{tabular}

$\beta$-keto esters with $\mathrm{p} K_{\mathrm{a}}$-values around 10.5 a DCF value of medium order; 2-oxocyclopentanecarboxylate (1) and ethyl 2-methylacetoacetate (3) are $\alpha$-sbstituted $\beta$-keto esters with $\mathrm{p} K_{\mathrm{a}}$ values of about 12 , which show very low DCF values.

The value of the DCF of iron bis-diktonato complexes thus shows a significant correlation to the acid strength of the coordinating diketone ligands. Since the DCF is a measure of covalency in

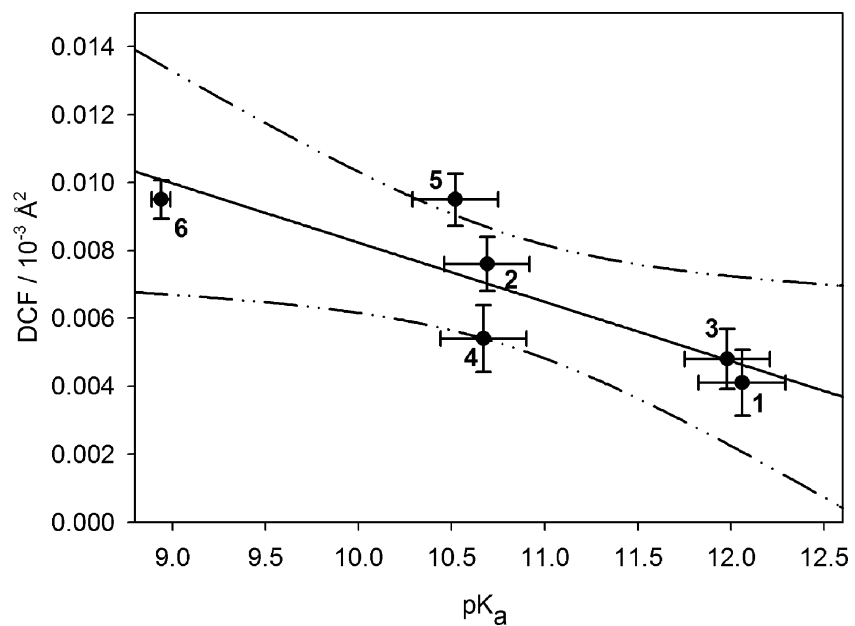

Figure 2. Plots of the displacement correlation factor against the $\mathrm{p} K_{\mathrm{a}}$ of the diketones $\mathbf{1}, \mathbf{2}, \mathbf{3}, \mathbf{4}, \mathbf{5}$, and $\mathbf{6}$ as calculated with ACD laboratories for solaris. The regression function is shown as solid line, and its analytic function is given in the text. The $95 \%$ confidence interval is plotted as double-dotted dashed line. 
metal complexes, the degree of covalency is therefore also correlated to the $\mathrm{p} K_{\mathrm{a}}$-value. It is well-known that the acidic strength of diketones is directly linked to the stability of the formed carbanion, which is in a simple picture connected to the number of mesomeric structures. Naturally, symmetric diektons like 2,4pentadione show a high number of mesomeric structures, with equal contributions of both oxygen atoms to the localization of the negative charge. This charge distribution is changed in unsubstituted $\beta$-keto esters by the introduction of the electron withdrawing ester group. In these cases the anion is prefarrably stabilized by the ester group, with a higher contribution of the carboxy group to the distribution of the negative charge, that is, a asymmetry to the distribution of the negative charge is introduced, which becomes even more significant with a substitution in $\alpha$-position, as in this cases the localization of the negative charge at the ester group is even higher. In both latter cases the stability of the carbanion is reduced in comparson to the 2,4-diketone and the $\mathrm{p} K_{\mathrm{a}}$-value increases. ${ }^{17}$

In conclusion, the covalency of iron(III) bis-diketonato complexes is correlated to the symmetry of the diketoneate anion by the $\mathrm{p} K_{\mathrm{a}}$-value. A similar trend was found for the iron affinity of $\beta$-keto esters by means of ESI mass spectrometry. ${ }^{18}$ However, by this method, the net effect of ionic and covalent bond contributions as well as steric effects is probed, while with the present work, direct insights into the covalency of iron(III) diektonate complexes become directly available.

The results of the present study do not allow any correlation between the degree of covalency and the reactivity of the coordinating diketone (cf. Scheme 1) as the diketones with the highest and second lowest yield $(\mathbf{1}, \mathbf{3})$ belong both to the group with the lowest DCF. Thus, the reason for the observed reactivities needs further clarification.

With the presented work it could therefore be shown that the degree of covalency metal-ligand bonds can be probed by a combined XAFS, Raman, and UV/vis study, which is particularly useful in cases of iron-containing systems, where magnetic resonance techniques usually fail. It is thus suited to contribute to the clarification of different reactivities in catalytic reactions.

\section{Conclusion}

With this study, chemical information in EXAFS data beyond coordination geometry, coordination numbers, and bond distances is extracted for the first time by thorough analysis of the EXAFS DWF in order to obtain qualitative insights into the degree of covalency of iron(III) bis-diektonato complexes. For this purpose, a combined EXAFS-Raman method was applied in order to extract the displacement correlation factor (DCF). The DCF is a measure of correlated motion between the X-ray absorber and backscatterer. Because the extent of correlation is directly proportional to the degree of covalency between the two atoms, the EXAFS DWF provides a comparative tool for the covalency between the metal and ligand atoms in transition metal complexes.

This was established for several iron(III) bis-diketonato complexes, which are of general interest, but play a special role in the iron-catalyzed Michael addition reaction, ${ }^{19}$ where it could be shown that the relative covalencies of the different iron(III) bis-diketoneato complexes cannot explain the different reactivities of the used diketone compounds.

In advance of a detailed DWF analysis, the comparability of the complexes had to be ensured, which was achieved by UV/ vis and Raman analysis. It was demostrated that the extent of correlated motion and thus the relative covalency is highly correlated to the acid strength of the ligands as reflected in the $\mathrm{p} K_{\mathrm{a}}$ value. The results offered completely new insights into this behavior, as ESI mass-spectrometric studies could only reveal tendencies of the affinity of the ligands to the iron center, which includes also ionic and steric interactions. ${ }^{18} \mathrm{~A}$ qualitative explanation of the relative covalencies was given, but this point required further quantification in the future. Notably, X-ray emission methods such as resonant inelastic X-ray scattering (RIXS) offer a great potential in this direction, ${ }^{20}$ as d-electron densities at the iron center and charge transfer effects ${ }^{21}$ can be determined, also in combination with iron $\mathrm{L}_{3}$-edge $\mathrm{X}$-ray absorption spectroscopy. ${ }^{22}$

Acknowledgment. Hasylab (Hamburg) is kindly acknowledged for provision of beamtime, and Dr. D. Zajac for his support during the beamtime. Volker Bauch is acknowledged for his efforts in course of the data analysis.

Supporting Information Available: The complete Raman and UV/vis spectra of all investigated solutions are available in the Supporting Information, as well as the raw EXAFS spectra and a comparison of the experimental and calculated EXAFS functions.This material is available free of charge via the Internet at http://pubs.acs.org.

\section{References and Notes}

(1) Spijksma, G. I.; Bouwmeester, H. J. M.; Blank, D. H. A. Inorg. Chem. 2006, 45, 4938.

(2) (a) Bauer, M.; Bertagnolli, H. Z. Phys. Chem. 2009, 223, 877. (b) Bauer, M.; Müller, S.; Kickelbick, G.; Bertagnolli, H. New J. Chem. 2007, $31,1950$.

(3) Rössle, M.; Christoffers, J. Tetrahedron 2009, 65, 10941.

(4) Bauer, M.; Kauf, Th.; Christoffers, J.; Bertagnolli, H. Phys. Chem. Chem. Phys. 2005, 7, 2664.

(5) (a) Christoffers, J. Chem. Commun. 1997, 943. (b) Christoffers, J. J. Chem. Soc., Perkin Trans. 1997, 3141. (c) Christoffers, J. Tetrahedron Lett. 1998, 39, 7083. (d) Christoffers, J.; Oertling, H. Tetrahedron 2000, 56, 1339. (e) Christoffers, J.; Oertling, H.; Leitner, M. Synlett 2000, 349.

(6) Pelzer, S.; Kauf, T.; van Wüllen, Chr.; Christoffers, J. J. Organomet. Chem. 2003, 684, 308.

(7) (a) Koningsberger, D. C.; Prins, R. Ed. Chemical Analysis, X-ray Absorption; John Wiley \& Sons: 1988; Vol. 92;(b) Teo, B. K. EXAFS: Basic Principles and Data Analysis; Springer: Berlin, Heidelberg, 1986.

(8) (a) Beni, G.; Platzman, P. M. Phys. Rev. B 1976, 14, 1514. (b) Greegor, R. B.; Lytle, F. W. Phys. Rev. B 1979, 20, 4902.

(9) Cyvin, S. J. Spectrochim. Acta 1959, 56.

(10) (a) Boland, J. J.; Baldeschwieler, J. D. J. Chem. Phys. 1984, 80, 3005. (b) Boland, J. J.; Baldeschwieler, J. D. J. Chem. Phys. 1984, 81, 1145 .

(11) Ertel, T. S.; Bertagnolli, H. Nucl. Instrum. Methods. Phys. Res., Sect. B 1995, 73, 199 .

(12) (a) Ressler, T. J. Synchrotron Rad. 1998, 5, 118. (b) Ertel, T. S.; Bertagnolli, H.; Hückmann, S.; Kolb, U.; Peter, D. Appl. Spectrosc. 1992, 46, 690. Newville, M.; Livins, P.; Yacoby, Y.; Rehr, J. J.; Stern, E. A. Phys. Rev. B 1993, 47, 14126.

(13) (a) Binsted, N.; Hasnain, S. S. J. Synchrotron Rad. 1996, 3, 185. (b) Filipponi, A.; Di Cicco, A.; Tyson, T. A.; Natoli, C. R. Solid State Commun. 1991, 78, 265. (c) Rehr, J. J.; Mustre de Leon, J.; Zabinsky, S. I.; Albers, R. C. J. Am. Chem. Soc. 1991, 113, 5135. (d) Hayakawa, K.; Hatada, K.; D’Angelo, P.; Della Longa, S.; Natoli, C. R.; Benfatto, M. J. Am. Chem. Soc. 2004, 126, 15618. (e) Benfatto, M.; Solera, S. A.; Ruiz, J. G.; Chaboy, J. Chem. Phys. 2002, 282, 441.

(14) Iball, J.; Morgan, C. H. Acta Crystallogr. 1967, 23, 239.

(15) Handa, M.; Miyamoto, H.; Suzuki, T.; Sawada, K.; Yukawa, Y. Inorg. Chim. Acta 1992, 203, 61.

(16) Nakamoto, K. Infrared and Raman Spectra of Inorganic and Coordination Compounds; John Wiley \& Sons: 1986.

(17) Ebel, H. F. Metallorganische Verbindungen, In Methods in Organic Chemistry, 4th ed.; Houben-Weyl: 1952; Vol. XIII/1, 1970.

(18) Trage, C.; Schröder, D.; Schwarz, H. Chem.-Eur. J. 2005, 11, 619.

(19) Christoffers, J. Synlett 2001, 723.

(20) Bauer, M.; Gastl, Chr Phys. Chem. Chem. Phys. 2010, 12, 6520.

(21) Glatzel, P.; Bergmann, U. Coord. Chem. Rev. 2005, 249, 65.

(22) de Groot, F. Chem. Rev. 2001, 101, 1779.

JP1079718 